\title{
EDUCAÇÃO ESCOLAR E REDES DE CONHECIMENTOS EM MOÇAMBIQUE: \\ colonialidades, epistemicídios e questões atuais
}

Roberto da Costa Joaquim Chaua

Resumo

Produzido a partir da compreensão histórica da educação em Moçambique, da imersão no cotidiano das escolas do Norte do país e dos embates em torno da relação entre redes de conhecimentos, mormente, a escola e os ritos de iniciação, esse artigo mapeia colonialidades, epistemicídios e questões ligadas à educação moçambicana. Elege a metáfora diálogo à volta da fogueira enquanto espaçotempo de resistência e necessário para compreensão das conflitualidades e negociações subsistentes nos processos educativos. A fogueira se apresenta enquanto dispositivo de estada em uma dimensão humana, pela qual ideias de liberdade e subversão vem à tona representadas nos atos humanos de comer, se relacionar, fazer histórias e compartilhá-las constituindo símbolo dos mecanismos acionados para lutar, viver e sonhar em contexto de miséria.

Palavras-chave: educação; conhecimentos; colonialidades; resistências

\section{SCHOOL EDUCATION AND KNOWLEDGE NETWORKS IN MOZAMBIQUE:} colonialities, epistemicides and current issues

\section{Abstract}

Drafted from the historical understanding of the education system in Mozambique, from immersion in the daily life of schools of the North of the country and from clashes over the relationship between knowledge networks, particularly, the school and the initiation rites, this article historically maps colonialities, epistemicides and issues of education in Mozambique. From this mapping, it chooses the metaphor dialogue around the bonfire as space-time of resistance and the dialogue necessary to understand the conflicts and negotiations that subsists over there. The bonfire presents itself as a living environment in a human dimension, through which ideas of freedom and subversion come out represented in the human acts of eating, warming up, making stories and sharing them constituting a symbol of mechanisms activated to fight, live and dream in a context of misery.

Keywords: education; knowledge; colonialities; resistances

\section{EDUCACIÓN ESCOLAR Y REDES DE CONOCIMIENTO EN} MOZAMBIQUE: colonialidad, epistemicidio y cuestiones actuales

\section{Resumen}

El presente artículo se produce a partir de la comprensión histórica de la educación en Mozambique, de la inmersión en el cotidiana de las escuelas en el norte del país y los enfrentamientos que rodean la relación entre las redes del conocimiento, especialmente la escuela y los ritos de iniciación. El mismo mapea colonialidad, epistemicidio y cuestiones ligadas a la educación mozambiqueña. Eligiendo la metáfora del diálogo alrededor de la hoguera como un espacio-tiempo de resistencia necesaria para la comprensión de los conflictos y las negociaciones que persisten en los procesos educativos de la región. La hoguera se presenta como un dispositivo vivo en una dimensión humana, a través del cual las ideas de libertad y subversión aparecen en los actos humanos de comer, relacionarse, hacer historias y compartirlas, simbolizando los mecanismos utilizados para luchar, vivir y soñar en un contexto de miseria.

Palabras clave: educación; conocimiento; colonialidad; resistencias 


\title{
CONSIDERAÇÕES INICIAIS
}

\author{
Não vamos esquecer o tempo que passou, \\ Quem pode esquecer o que passou!? \\ O pai de cinco filhos chamado rapar, \\ A mãe de cinco filhas chamada rapariga, \\ Fascista de quinze anos chamado Sr. Doutor, \\ Quem pode esquecer o que passou!?1
}

Desde a independência nacional, em 1975, o pensamento oficial vem reconhecendo a educação escolar como marco importante e na ideia moderna - instrumento fundamental para o crescimento económico e desenvolvimento social, visando à promoção do bem-estar dos cidadãos. Diante desse reconhecimento mudanças têm sido efusivamente adotadas. O fulcro das mudanças está, a meu ver, na expressão da necessidade de se repensar as opções políticoideológicas e financeiras em constante alteração no país. Em outra vertente, o foco educacional tem uma constante: ainda se encontra na necessidade de expandir a rede escolar e melhorar a qualidade e o acesso, considerando que a taxa de analfabetismo ${ }^{2}$ era de $94 \%$ no ano da independência e dados de 2019 apontam que 38,6\% das crianças de 6 aos 17 anos de idade continua fora da escola. Nas províncias do Norte de Moçambique, onde se localiza Nampula, o locus desse diálogo, registam-se as maiores taxas de analfabetismo. Dados de 2007 indicavam, por exemplo, 62,3\% para Nampula, 66,6\% em Cabo Delgado e a província do Niassa com uma taxa de analfabetismo de 61\% (MINEDH, 2017; INE, 2019).

No campo político e legislativo, pode se afirmar que a grande mudança no contexto educativo começou com a adopção da primeira Lei do Sistema Nacional de Educação (SNE), em 1983, através da Lei n. 4/83, de 23 de março, que foi revista em 1992 pela Lei n. 6/92, de 6 de maio, também revista pela Lei n. 18/2018, de 18 de dezembro - em vigor desde 2019. Nesse percurso de um pouco mais de 35 anos desde a adopção da primeira Lei do SNE ainda houve em 2004 a implementação do novo Plano Curricular do Ensino Básico. Essas mudanças foram causadas e indicam os vários momentos históricos que chamaremos à discussão mais adiante.

No país, o campo educacional está marcado por relações internas e externas que levam a desafios deveras complexos. Os contextos de referência para pensar a educação escolar desenvolvem-se, segundo os filósofos e educacionistas moçambicanos Castiano e Ngoenha (2013) em, pelo menos, três eixos:

Primeiro eixo: expandir a todos os cantos do país o acesso à educação escolar, o que "leva a uma aceitação implícita da escola em suas acepções universal, global e moderna".

Segundo eixo: mais interno, tem como tendência debater e questionar a qualidade de educação (muitas vezes, a que o primeiro eixo assume). Essa qualidade, no entanto, se baseia em indicadores 'traçados' em fóruns internacionais (relação aluno/professor; qualificação dos professores; material didático disponível; infraestruturas escolares e outros).

$\mathrm{O}$ terceiro eixo tem como tendência questionar a legitimidade dos saberes que estão sendo transmitidos e produzidos pela escola moçambicana. Este eixo assenta-se na necessidade de sairmos do paradigma ocidental de educação. (CASTIANO, NGOENHA, 2013, p. 12).

\footnotetext{
${ }^{1}$ Verso de uma canção popular / revolucionária bastante entoada por Samora Machel, Primeiro Presidente de Moçambique independente.

${ }^{2}$ Tenho ciência da possibilidade de problematizar o termo analfabetismo e seus usos. Porém, nesse texto se procede de forma diferente e é utilizado na acepção adoptada pelas instituições educativas de Moçambique enquanto percentagem de pessoas com 15 anos ou mais que não sabem ler ou escrever.
} 
Os dois primeiros estão sustentados nas ideias iluministas da educação como possibilidade "para o povo tomar o poder". Estes assentam-se, também, e como corolário dos compromissos que o país vem assumindo em nível internacional, nos Objetivos de Desenvolvimento do Milénio atuais Objetivos de Desenvolvimento Sustentável; na Declaração de Educação Para Todos de Jomtien; na universalização de educação básica assumida em 2000 no Dakar-Senegal e, que desencadeou na adoção da conhecida Iniciativa Acelerada de Educação Para Todos (Fast Track Iniciative / Education For All - FTI / EFA), que conta com o financiamento do Banco Mundial e do Fundo Monetário Internacional. O terceiro eixo é mais consentâneo com o debate axiológico que vem permeando a discussão filosófica, política e epistemológica em muitos países africanos.

Entendo, entretanto, que é necessário assumir que o processo educativo moçambicano está submerso numa complexidade de relações, tornando-se difícil situar-se em determinado eixo de interrogação sem considerar as lutas (muitas vezes de sobrevivência) que caracterizam o país. Nesse artigo, busco assentar-me no terceiro eixo, ponderando que a escola se situa no prisma do que Mbembe (2013) chama de "em primeiro lugar, comer" e que evidencia um conjunto de dramas existenciais, entendidos por Ngoenha (2017) como um conjunto de situações de miséria que notificam a penúria de "ser" humano. Tais dramas caracterizam-se pelo espectro de violência e guerra que tem ameaçado o país, basta lembrar a metáfora do Abadon, figura apocalíptica do abismo, usada pelo autor para pensar a hodierna globalização da violência, traduzida em seus signos mais comuns: a fome, a opressão económica, o desemprego, as desigualdades, terrorismos e, sobretudo, a guerra que, para o filósofo, é "[...] o verdadeiro fenómeno global, num duplo sentido: ela está em todos os lugares e, quando aparece localmente, é ainda universal" (NGOENHA, 2017, p. 24). Minha escolha se pauta pelo entendimento de que, não obstante as diferentes questões que se colocam à escola em Moçambique, não se pode desfigurar sua relevância em constituir bases importantes à formação do cidadão e da cidadã moçambicana. Nesse contexto, pensar com ela é também uma tarefa de se interrogar e buscar em suas práticas processos que se querem emancipatórios.

Como parte do que tenho vindo a pensar nas pesquisas desde o mestrado, o texto tem como objetivo mapear - a partir de uma leitura histórica da educação - colonialidades, epistemicídios e questões ligadas à educação moçambicana e articulá-las às reflexões que venho produzindo nos encontros em escolas da província de Nampula. Busca, também, no contexto das colonialidades, pensar as relações de produção de conhecimento no âmbito dos cotidianos educativos. O pressuposto é de que em Moçambique, ao contrário das unanimidades que apregoa o processo colonial, existe um tensionamento característico de uma diversidade epistemológica que coloca um conjunto de conflitualidades e negociações entre a escola e outras diferentes instâncias de produção de conhecimentos. $\mathrm{Na}$ senda dos diálogos necessários à compreensão dessas realidades a metáfora dos diálogos à volta da fogueira surge como possibilidade para fundar interrogações. O contexto educativo é entendido como situado no paradoxo entre a satisfação das necessidades difusas e a interrogação dos processos que busca legitimar. Assim, a fogueira é entendida não só como um espaço geográfico concreto, mas como espaço político, como manifestação de experiência e sentido, como os marcos formais e informais dentro dos quais se formam os questionamentos e as interações sociais cotidianas (BRINGEL, ECHART, 2008).

Ciente de que opções e escolhas são feitas em consonância com os objetivos, metodologias adotadas e principalmente o lugar que escolhemos "para contar o nosso conto" considero, no texto, que inúmeras experiências determinam a vivência educacional de hoje. Preciso que a memória é necessária no desvencilhar do que foi conduzido, apesar dos seus limites, e constituiu inspiração para se prosseguir nas interrogações sobre educação. Neste sentido, amparo-me nas palavras em epígrafe para, com Samora Machel, nacionalista e proclamador da independência, reafirmar a pergunta: quem pode esquecer o que passou!? Dessa, indico 
a necessidade de não esquecermos, antes de qualquer debate atual, o fardo colonial a que o país está imerso. Meu amparo tem causa: muitos dos nossos debates e discussões de educação, conhecimentos e culturas beiram à naturalização de práticas coloniais ainda comuns aos nossos cotidianos. Concordo com Carlos Moore (2011, p. 23) quando afirma que "[...] abstrair o mundo negro de seu legado catastrófico pode iludir nossa percepção, mergulhando-nos numa visão dominada pela 'falsa impressão' de que testemunhamos uma realidade feita de indecifráveis incoerências e de caos sem causas precursoras".

\section{POR UMA LEITURA HISTÓRICA DA EDUCAÇÃO MOÇAMBICANA: COLONIALISMO, DILEMAS E QUESTÕES ATUAIS}

A caracterização colonial em sua "máquina de esquecimento" é imaculada por um discurso que impinge a colonização enquanto possibilidade civilizadora dos povos africanos. A civilização é apresentada, nesse discurso, como símbolo do desenvolvimento da razão europeia em suas diferentes esferas. O martinicano Aimé Césarie é, certamente, um dos importantes intelectuais da diáspora negra que buscou modos de tornar cada vez mais sólidos os contornos da barbárie do que foi esse empreendimento colonial. Sua obra Discurso sobre o colonialismo é um empenho para danificar e impedir o funcionamento da "máquina do esquecimento" sobre o que foi o colonialismo. A essência do colonialismo, segundo Césarie, escreve Mário de Andrade no prefácio da obra, reveste-se de dois aspectos: o de um "[...] regime de exploração desenfreada de imensas massas humanas que tem sua origem na violência e só se sustém pela violência" e o de uma "forma moderna de pilhagem" (CÉSARIE, 1978, p. 7). Césarie $(1978$, p. 13) traz à tona o que na verdade se constituiu o colonialismo: uma catársis justificada pelo colonizador como projeto civilizatório, mas vivida pelo colonizado como barbárie:

Uma civilização que se revela incapaz de resolver os problemas que seu funcionamento suscita, é uma civilização decadente.

Uma civilização que prefere fechar os olhos aos seus problemas mais cruciais, é uma civilização enferma.

Uma civilização que trapaceia com os seus princípios, é uma civilização moribunda.

O que não vamos esquecer - como sugere a epígrafe - é o que a colonização fez ao colonizado: O pai de cinco filhos chamado rapaz; A mãe de cinco filhas chamada rapariga; Fascista de quinze anos chamado Sr. Doutor. Césarie (1978, p. 26) prefere uma equação: colonização = coisificação:

Eu, eu falo de sociedades esvaziadas de si próprias, de culturas espezinhadas, de instituições minadas, de terras confiscadas, de religiões assassinadas, de magnificências artísticas aniquiladas, de extraordinárias possibilidades suprimidas. Lançam-me à cara factos, estatísticas, quilometragens de estradas, de cacau, de caminhos-de-ferro.

Mas eu falo de milhares de homens sacrificados no Congo-Oceano. Falo dos que, no momento em que escrevo, cavam à mão o porto de Abidjan. Falo de milhões de homens arrancados aos seus deuses, à sua terra, aos seus hábitos, à sua vida, à vida, à dança, à sabedoria.

Lançam-me em cheio aos olhos toneladas de algodão ou de cacau exportado, hectares de oliveiras ou de vinhas plantadas.

Mas eu falo de economias naturais, de economias harmoniosas e viáveis, de economias adaptadas à condição do homem indígena desorganizadas, de culturas de subsistência destruídas, de subalimentação instalada, de desenvolvimento agrícola orientado unicamente para benefício das metrópoles, de rapinas de produtos, de rapinas de matérias-primas. 
A pretensão civilizadora do empreendimento colonial se dava consubstanciando o trabalho, enquanto forma primária da acumulação capitalista que se expandia na época, com a ação educativa como esforço complementar e mantenedor da ideologia colonial. Assim, a colonização, para além de todas as outras formas de dominação por que é conhecida, foi também uma dominação epistemológica, uma relação extremamente desigual entre saberes que conduziu à supressão de muitas formas de saber próprias dos povos e das nações colonizadas. A colonização relegou muitos conhecimentos, situados fora de seu prisma hegemônico, para um espaço de subalternidade, bem como, a sua não-existência (SANTOS, 2010). Ao longo da história, ao continente africano foi imposto um paradigma educacional da Europa (CASTIANO, NGOENHA, 2013) e nesta imposição a educação escolar, grandemente alijada aos contextos africanos, foi considerada pela Europa e pelos educados sob sua hegemonia, como uma "arma" poderosa para conduzir os então indígenas à civilização. Salazar, então chefe do governo português, eufemicamente sintetizava essa pretensão quando, em 1957, dizia: "Acreditamos que existem raças decadentes ou se preferem, atrasadas, a quem sentimos o dever de conduzir para a civilização - tarefa esta de formação de seres humanos que deve ser levada a cabo de maneira humanizante".

Ao contrário do que acontecia nas áreas de influência de outros países europeus, o sistema escolar colonial em Moçambique, com génese em meados do século passado, constituiu possibilidade formativa, através do apoio da Igreja Católica, só para uma mínima parte da população por pressões de outros países colonizadores. Pior, é que mesmo quando os nativos entenderam que a educação escolar poderia ser utilizada subversivamente ${ }^{3}$, ela foi segregacionista e inalcançável em grande parte do território moçambicano. A imposição ao sistema educativo europeizado tinha como pano de fundo o entendimento da necessidade de busca de outras formas de manutenção da hegemonia colonial sem passar pelo Xibalo - trabalho forçado.

Césarie (1978), portanto, foi assertivo ao apontar o dilaceramento de que se constituiu o empreendimento colonial. Mas, no contexto da pós-independência, a colonialidade vigorou de formas não muito diferenciadas. Como que concordando com a afirmativa de Certeau (1995) de que "[...] toda autoridade repousa sobre uma adesão" no que chamamos Moçambique independente recrudesceram ideias que tinham como principal objetivo: "[...] destruir a Velha Sociedade, profundamente impregnada de vícios e defeitos, em que florescem as ideias conservadoras, supersticiosas, individualistas e corruptas [...] para construir sobre os seus destroços a Sociedade Nova" (MAZULA, 1995, p. 137). Na construção dessa "nova sociedade", papel importante também era reservado à educação escolar, em que a Língua Portuguesa foi oficializada com o intuito de permitir uma "verdadeira unidade nacional" e, as línguas maternas / nacionais foram proibidas. Os ideais autóctones foram julgados como improcedentes na condução do país para uma sociedade livre da tradicionalidade, da burguesia e para a formação ideológica do chamado Homem Novo.

A burguesia era entendida, nessa esfera, com todos os resquícios do colonialismo. O que seria então essa tradicionalidade característica das chamadas sociedades tradicionais? Prevaleceu nas políticas pós-independentistas uma errônea compreensão das formas de resistência adotadas pelas autoridades tradicionais para "conviver" com o sistema colonial. O poder tradicional era entendido como "colaborador" do colonialismo e isso se revelou em "práticas de desprezo", tal como acontecia no período colonial, aos conhecimentos endógenos ligados aos sistemas de viver das comunidades e grupos étnicos moçambicanos. A primeira Lei do SNE aprovada pela

${ }^{3}$ Foi a partir dos seminários que se formou a maior parte dos dirigentes de Moçambique e nasceu o núcleo que criou a Frente de Libertação de Moçambique. A educação escolar que reproduzia o sistema social colonial acabava por formar aqueles que o iriam contestar. 
Assembleia Popular de Moçambique, em 1983, dizia bem, em sua parte introdutória, o que se achava dos ideais autóctones, a que se chamava de sociedades tradicionais:

$\mathrm{Na}$ sociedade tradicional, a educação transmitia conhecimentos e técnicas acumuladas na prática produtiva, inculcava o seu código de valores políticos, morais culturais e sociais e dava uma visão idealista do mundo e dos fenómenos da natureza. Pela iniciação e rito, pelo dogma e superstição, pela religião e magia, pela tradição, o indivíduo era preparado para aceitar a exploração como uma lei natural e assim reproduzida no seu grupo etário, na sua família, na sua tribo, etnia e raça (LEI n. 4/83).

A Lei concebia as práticas e os conhecimentos imanentes às ditas sociedades tradicionais, ou seja, indígenas, como responsáveis pelos processos de exploração. Assim, no Artigo 1 do Capítulo VI da mesma Lei constava que "[...] o sistema nacional de educação tem como objetivo central a formação do Homem Novo, um homem livre do obscurantismo, da superstição e da mentalidade burguesa e colonial, um homem que assume os valores da sociedade socialista". Esse seria, portanto, o exemplo dos sistemas de saberes e práticas disciplinares implementados sob o pretexto da construção do Estado-nação em Moçambique. Tal concepção deixava de fora um diálogo que se esperava entre as diferenças que caracterizam o país, não superando, nesse contexto, as colonialidades que caracterizavam a escola e o contexto colonial.

Em termos objetivos, ou seja, nessa apropriação de um ideal de educação colonial, ressalvando a adequação dos conteúdos escolares, o sistema educativo estava sendo severamente afetado pela guerra civil em irrupção em Moçambique. O conflito armado entre o governo e a RENAMO $^{4}$ impôs duras perdas ao país. No sector da educação, houve impactos profundos, principalmente nas infraestruturas escolares. No período de 1981 a 1987, foram encerradas aproximadamente $50 \%$ das escolas primárias, $13 \%$ da rede escolar secundária, $22,5 \%$ dos centros de formação de professores e vários centros ou unidades de alfabetização de adultos. O êxodo de milhares de pessoas das zonas rurais para as zonas urbanas à procura de proteção esvaziou a rede escolar de certas regiões do país. Em 1992, o ensino primário contava com apenas 1,2 milhão de alunos, um número equivalente ao existente em $1983^{5}$.

Com o prevalecer da ideia de construção de nação moçambicana e com a adopção da referida Lei, em poucos anos, entre a conquista da independência política e a construção dos pilares do que seria Moçambique independente, passou-se de um modelo de escola europeia concebido para funcionar numa sociedade que se pretendia capitalista para um modelo de escola europeia concebido para funcionar numa sociedade que se pretendia socialista, ou seja, como referem Castiano, Ngoenha (2013), passou de valores extremos a valores extremos, mas todos distantes da realidade dos moçambicanos que deveriam ser os principais beneficiários do sistema.

A introdução do Estado de Direito Democrático, em 1990, e o fim do conflito armado, em 1992, criam a base para a adoção de um novo SNE "adequado" às novas vivências e orientações políticas. Mas o que significou tal mudança no contexto das ideias e relações sobre escola e educação anteriormente referidas? A Lei n. 6/92, de 6 de maio, foi aprovada com o intuito de adequar as disposições contidas na Lei do SNE de 1983, mas seus efeitos subverteramse apenas no campo organizativo e pedagógico do sistema. Embora no Artigo 4 referisse que o SNE deveria passar a "[...] valorizar e desenvolver as línguas nacionais, promovendo a sua introdução progressiva na educação dos cidadãos", os objetivos do sistema centraram-se ainda em: 1. proporcionar o acesso ao ensino de base aos cidadãos moçambicanos, contribuindo para garantir a igualdade de oportunidades de acesso a uma profissão e aos sucessivos níveis de

${ }^{4}$ Resistência Nacional Moçambicana.

${ }^{5}$ Dados disponíveis num relatório publicado pelo AfriMAP e pela Open Society Initiative for Southern Africa Moçambique: A Prestação Efectiva de Serviços Públicos no Sector da Educação, 2012. 
ensino; 2. dar formação integral ao cidadão para que adquira e desenvolva conhecimentos e capacidades intelectuais, físicas, e na aquisição de uma educação politécnica, estética e ética; 3. dar formação que corresponda às necessidades materiais e culturais do desenvolvimento económico e social do país; 4. detectar e incentivar aptidões, habilidades e capacidades especiais nomeadamente intelectuais, técnicas, artísticas, desportivas e outras. (Lei n. 6/92, Capítulo IV, Artigo 10).

Nesses objetivos do novo SNE não estão referenciadas as "sociedades tradicionais" de outrora, nem o Homem Novo, menos ainda a ideia "ideológica" de formação cidadã que se esperava. Se era histórica uma miragem à formação cidadã esperada (a assimilação no período colonial e o Homem Novo no pós-independência), essa Lei deixou um vazio, uma lacuna. Entretanto, no contexto das relações de conhecimentos e "cosmogonias" vigorantes, essa supressão no campo político-legislativo não significou, contudo, a cessação de conflitualidades e interrogações entre a educação escolar e as diferentes redes de conhecer que vigoram dentrofora do sistema escolar.

A partir de 1999 começa a ser desenvolvida a reestruturação curricular do ensino básico em Moçambique e um dos pontos utilizados para justificar essa necessidade de reestruturação, além do político-económico e educativo, é o contexto sociocultural do país, importante para conferir maior relevância à educação básica já que, segundo o texto curricular, pesquisas antropológicas sobre a interação entre a cultura tradicional e a escola oficial chegaram à conclusão de que há um desfasamento entre a ação educativa e a cultura das tradições locais. Esse desfasamento foi aferido a partir da análise de: práticas socioeconómicas e a divisão social do trabalho na comunidade, fatores que, muitas vezes, condicionam a participação das crianças nas atividades escolares e põem em causa o próprio valor da escola, pois muitas crianças, desde muito cedo, participam em atividades produtivas, ajudando os pais na machamba, guardando o gado e em outras tarefas domésticas em geral; os estereótipos relacionados com o género e notados quando os pais privilegiam a escolaridade dos rapazes, pois a divisão social do trabalho, na base do género, atribui às meninas, desde muito cedo, tarefas tradicionalmente consideradas da responsabilidade da mulher, o que dificulta o seu acesso à escola; a língua de ensino que em grande parte era diferente da língua materna dos alunos e, por fim, os ritos de iniciação - que a seguir tomo como exemplo das conflitualidades persistentes nos cotidianos escolares. (INDE, 2003).

Dessa forma, o Plano Curricular do Ensino Básico aprovado em 2003 e introduzido em 2004 sinalizava o começo das interrogações e reestruturações curriculares fundamentadas na percepção de que a educação tem que ter em conta a diversidade dos indivíduos e dos grupos sociais, para que se torne num fator, por excelência, de coesão social e não de exclusão. O Plano afirmava que as sociedades enfrentam o dilema da construção da aldeia global e a pertinência da defesa e desenvolvimento das identidades particulares / nacionais, não obstante o entendimento de que o principal desafio que se coloca ao currículo moçambicano era o de tornar o ensino mais relevante, no sentido de formar cidadãos capazes de contribuir para a melhoria da sua vida, da vida da sua família, da sua comunidade e do país, dentro do espírito da preservação da unidade nacional, manutenção da paz e estabilidade nacional, aprofundamento da democracia e respeito pelos direitos humanos, bem como da preservação da cultura moçambicana. (INDE, 2003; CASTIANO, NGOENHA, 2013).

Embora o mesmo texto curricular também se refira que "[...] não se trata de transformar a escola num instrumento privilegiado para a preservação das culturas tradicionais, mas sim num espaço de interação entre as culturas das comunidades e os novos paradigmas da cientificidade" (INDE, 2003, p. 13), considero serem esses os primeiros passos do questionamento da educação escolar, com base em aspectos não "puramente didáticos" e que consideram os sistemas de conhecer e viver das tradições moçambicanas. Aqui o sistema educativo escolar se abre para um 
novo conjunto de dilemas: assumir uma educação arraigada no neoliberalismo e na satisfação de necessidades modernas, ao mesmo tempo em que a requer tradicionalista e imbuída de axiomas endógenos. Tais dilemas vigoram e encontram respaldo nas transformações vigentes desde a adopção da Lei n. 18/2018.

\section{ESCOLA, RITOS DE INICIAÇÃO E PRODUÇÃO DE CONHECIMENTOS}

Foi sobre os ritos de iniciação ${ }^{6}$ em Moçambique que desenvolvi minha pesquisa de mestrado. Nela, detinha-me a uma simples proposição: os ritos de iniciação se constituem em espaçostempos de produção de conhecimentos, entendidos como conjunto de sentidos e significações, sobre a vida e o "ser" em várias comunidades. Essa produção, importante na vida de muitos moçambicanos não é incluída nos palanques das epistemologias dos "mundos dos nossos mundos". O que me moveu para essa pesquisa, além do estranhamento que já me era frequente desde meu primeiro contacto com o Norte de país foi, principalmente, a minha experiência como professor na Escola Secundária e Técnica Profissional de Mariri, Distrito de Ancuabe, Província de Cabo Delgado. Em um momento da aula de gestão de recursos, ao discutirmos sobre algumas práticas locais, apresentei-me como não-iniciado e despertei reações de estranheza dos/das alunos/as. Esse episódio fez-me atentar que, no cotidiano dessas escolas, tal como eu, existia em interação e tensão para aqueles/as alunos/as que passaram pelos ritos de iniciação à vida de adultos outros/as alunos/as moçambicanos/as que não passaram por esses ritos. A ideia "comum e imbricada" nesse contexto social a que me refiro é de que os ritos de iniciação, além de uma "instância" reguladora e atribuidora da qualificação ser / tornar-se Homem / Mulher são um campo educativo de participação obrigatória. Aí, eu me descobria uma eterna "criança". Poderia eu ensinar na escola ou nas famílias?

Além do sentimento de não pertença a esse mundo "do constructo social" que me se descobria, várias questões permeavam as minhas práticas cotidianas na escola, procurando legitimidade diante das dúvidas sobre o meu ser e o agir em sociedade. Assim, como não-iniciado por não ter passado por esse processo - ritos de iniciação - considerei necessário, com a pesquisa de mestrado, um repensar e um reencontro com os mesmos, buscando, como objetivo principal, compreender no meio dessa relação ou não relação - minha com os ritos, os ritos comigo, minha com os sujeitos praticantes / iniciados e esses comigo - produções de conhecimentos "outros" que circulam em "nossos mundos" e fizeram falta em minha vida, determinando o não-Homem que fui / sou a partir do momento em que me descobri não-iniciado no contexto nortenho de Moçambique. Busquei, também, um retorno aos mesmos (ritos e praticantes) numa altura em que os posicionamentos discursivos quanto a sua importância e relevância são bastante contraditórios, principalmente quando olhados com os “óculos da modernidade". E, por fim, me interessou a compreensão sobre como se ditam e se produzem os cotidianos nos encontros dos sujeitos iniciados e não-iniciados, e as relações dessas práticas e seus praticantes com uma lógica renegadora e que prima por outras bastante "civilizatórias". Esse último objetivo colocou-me na emergência de dialogar sobre educação e espaços escolares em Moçambique, o que constitui objeto da pesquisa que venho desenvolvendo atualmente no doutorado, tendo como locus as escolas da província de Nampula.

\footnotetext{
${ }^{6}$ Os ritos de iniciação são um conjunto de cerimonias que têm em vista a inserção dos "novos" na vivência comunitária sendo, por isso, realizáveis em várias fases / etapas da vida, com destaque para o nascimento, puberdade, casamento e morte, quando jogos, vidas, contos, corpos, canções etc. confluem, produzindo um imaginário de vivência cotidiana. A pesquisa referida teve como foco os ritos de iniciação a adultos na província de Nampula.
} 
Mas, qual seria a relação dos ritos de iniciação com a escola? Os ritos de iniciação são compreendidos desde o período colonial como matriz da educação tradicional, constituindo assim espaçostempos de muitas disputas. Basta ver os aspetos que caracterizaram sua desacreditação no período colonial, na pós-independência e em notícias e algumas pesquisas que, durante muito tempo, foram comuns em Moçambique. Cito na dissertação, como exemplo, uma pesquisa sobre relações de gênero, preocupada com as elevadas taxas de evasão da rapariga da escola, promovida por uma organização não governamental, a WLSA (siglas inglesas significando Mulher e Lei na África Austral) que, dentre várias, parte da ideia de que:

De facto, dados sobre a situação da rapariga e da criança (UNICEF, 2010) sugerem haver alguma convergência entre o que se chama de tradições e práticas culturais e as taxas brutas de frequência escolar. Com efeito, mesmo reconhecendo alguma melhoria nas assimetrias das taxas de frequência escolar entre rapazes e raparigas, fica evidente que uma das maiores barreiras no acesso e na permanência da rapariga na escola são as "tradições e a cultura", querendose referir com a expressão "tradições e a cultura" a aspectos que dificultam ou inviabilizam o acesso pleno ao direito à educação. Neste sentido, ainda que não se estabeleça à partida uma relação necessária entre os casamentos prematuros das raparigas e os ritos de iniciação, há um certo consenso de que estas práticas parecem influenciar negativamente as taxas de frequência do ensino primário. (OSÓRIO, MACUÁCUA, 2013, p. 26).

A pesquisa citada sugere seu embasamento na ideia de que as "tradições e as culturas" constituem umas das maiores barreiras à permanência da rapariga na escola, ao enfatizar o objetivo de pretender "[...] identificar qual o papel dos ritos na configuração das identidades sociais, particularmente as identidades sexuais, e como a 'educação ritual' pode deslocar o interesse da escola para o casamento ou para o trabalho" (OSÓRIO, MACUÁCUA, 2013, p. 30). Esse embasamento permite compreender a ideia de "fixação" da escola como axioma aceito e não discutível e que as ditas práticas culturais tradicionais constituem um entrave, sendo essas "secundárias" nas relações que se querem instituídas. Essa racionalidade na pesquisa parece bastante com uma das formas de produção de não-existência que caracteriza a racionalidade ocidental, a razão indolente (SANTOS, 2008). Ela ocorre, segundo Santos, de quatro formas:

Impotente: aquela que não se exerce porque pensa que nada pode fazer contra uma necessidade concebida como exterior a ela própria; arrogante: que não sente necessidade de exercer-se porque se imagina incondicionalmente livre e, por conseguinte, livre de demonstrar a sua própria liberdade; metonímica: que se reivindica como a única forma de racionalidade e, por conseguinte, não se aplica a descobrir outros tipos de racionalidade ou, se o faz, fá-lo apenas para as tomar em matéria-prima; e proléptica: que se aplica a pensar o futuro, porque julga que sabe tudo a respeito dele e o concebe como uma superação linear, automática e infinita do presente (SANTOS, 2008, p. 96).

Nessa concepção, os ritos não podem ser pensados fora da relação que estabelecem com a escola. Eles servem de matéria-prima para pensar e "aprimorar" a escola e, desse modo, propicia-se um processo de desacreditação formalizada dos espaçostempos ritualísticos. Portanto, talvez fosse melhor pensar que essas correlações se estendem a todo um contexto epistemológico instituído como dominante ou dominador. Talvez fosse possível falarmos de relações de poder em que a escola, por suas práticas "eurocentradas", se pretende dominadora do contexto em que está inserida. Uma escola metamorfoseada em um contexto de relações maiores que se estabelecem nas linhas abissais das epistemologias do mundo.

As dificuldades encontradas no âmbito da realização da pesquisa em apreço parecem evidenciar isso: 
[...] Contudo, as entrevistas às lideranças religiosas foram dificultadas pela desconfiança de que a equipa de pesquisa estivesse a "mando" do poder e pela existência de conflitos no seio de algumas das religiões, particularmente a islâmica (em Cabo Delgado), onde se defrontavam não só o controlo social sobre os crentes, mas, essencialmente, a procura de legitimidade conferida pelo poder político. (OSÓRIO, MACUÁCUA, 2013, p. 30)

Tal como aconteceu durante o período colonial e durante a realização de várias pesquisas "etnocêntricas", as populações locais sempre procuraram formas de burlar não só o poder político no primeiro caso, mas também, os pesquisadores. Precisamos atentar que essas relações estão embutidas em contextos em que a intenção é representar o outro, como fê-lo a razão indolente (SANTOS, 2008) da racionalidade ocidental que, pela metonimia apregoa a não-existência de outras alternativas credíveis à sua hegemonia.

Portanto, existe todo um contexto instituído e que, por diversos mecanismos, apregoa uma única forma de estar nos contextos educacionais e que, no cotidiano, nota-se a prevalência de problemas ligados à relevância dos conteúdos escolares para grande parte da população, elevada evasão escolar, falta de comprometimento das comunidades quanto aos processos instituídos nas escolas e até a interrogação da importância do trabalho escolar na vivência das comunidades. A legitimidade da escola não deixa de ser interrogada, principalmente, quando relacionada com outros espaçostempos de produção de conhecimentos que se podem / querem designar de "autóctones". Essas relações, além de gerar negociações, geram conflitualidades e tensionamentos, aos quais se torna profícuo produzir possibilidades de diálogo.

Meus interesses de pesquisa se assentam, então, na necessidade de aprofundamento destas faculdades de diálogos e venho defendendo a ideia de que tais diálogos podem ser desenvolvidos à volta da fogueira. Essa proposição parte da ideia de que, não obstante as constatações arroladas, seria ilusório no contexto atual, falar de uma escola que seja moçambicana sem se referir às diferenças inerentes ao seu mosaico. A ideia de uma escola moçambicana esconderia, por sua vez, as múltiplas referências, relações e diferenças internas existentes no país. Moçambique é constituído por várias nações étnicas pertencentes a um contexto com relações e não relações com os contextos bantu, africanos e de um mundo orientado por colonialidades que, em seu cotidiano, clama por ideais de abertura dialógica de fronteiras.

\section{CONSIDERAÇÕES FINAIS: DO DIÁLOGO À VOLTA DA FOGUEIRA - "EM PRIMEIRO LUGAR, COMER"}

Pensar diálogo à volta da fogueira, signo dos cotidianos de muitas comunidades moçambicanas, é adentrar em espaços não formalizados, em espaços jamais pensados pela produção científica. Como diz Fanon (2008, p. 43) esse pensar pode nos integrar nas ditas "tradições", nos trazendo certa tranquilidade, um estatuto e um certificado de estado civil. Constitui-se, assim, uma busca contra-hegemónica no sentido de atentar que, nas complexidades cotidianas, se situa o que Foucault chama de saberes sujeitados ou saberes das pessoas (FANON, 2008, p. 13) em que, de certeza jaz “[...] a memória dos combates, aquelas, precisamente, que até então tinha sido mantida sob tutela". A fogueira, portanto, se situa como espaçotempo para "[...] dessujeitar os saberes históricos e torná-los livres, isto é, capazes de oposição e de luta contra a coerção de um discurso teórico unitário, formal e científico" (FOUCAULT, 2005, p. 15). Ela assume, assim, uma metáfora oportuna, porque além de nos impelir à humanização das diferenças pelo fogo, alavanca a satisfação de necessidades primordiais (o frio e a fome, por exemplo), e mais, nos indica que essa satisfação pode avançar no sentido de trazer à roda outros diálogos, outras vivências e outros sonhos necessários à produção ética, estética e política da humanidade. Em síntese, ela pode ser compreendida como espacotempo do diálogo entre diferentes 
que coabitam o mesmo lugar e tempo e, nesse diálogo entra em jogo a troca intersubjetiva baseada em critérios humanizantes e que tenham como foco além de coisas de sonho e de verdade, a satisfação de necessidades difusas.

A consideração das necessidades atinentes ao diálogo à volta da fogueira é possibilidade de compreensão de uma das configurações que o imaginário das lutas políticas pode adoptar em sociedade colonizada e em tempos de miséria. O camaronês Achile Mbembe nos dá uma pista valiosíssima neste sentido. Para este filósofo e intelectual as lutas ideológicas e políticas de muitos africanos só são inteligíveis através do elemento - em primeiro lugar, comer. Na óptica do autor a metáfora em primeiro lugar, comer se torna importante, pois seria:

[...] errado subestimar ou minimizar a preocupação atual do indígena nos meios de se libertar da miséria e da pobreza através da aquisição de bens europeus. Mais preocupante ainda é que as lutas pelas subsistências e a violência que as acompanha estão em vias de se tornar uma das modalidades culturais mais pregnantes das sociedades africanas contemporâneas. (MBEMBE, 2013, p. 123).

Em seu Africa insubmissa: cristianismo, poder e estado na sociedade pós-colonial, Mbembe (2013) afirma que um dos modos de tornar viável qualquer pensar atinente ao questionamento do projeto simbólico em andamento no continente africano é o alcance / satisfação das necessidades materiais e alimentares dos africanos:

[...] por outras palavras, enquanto a estagnação econômica ou a distribuição desigual dos frutos de um crescimento hipotético persistirem nos países africanos, será impensável que o negro possa prescindir do exercício do poder do estado bruto, dado que, em primeira instância terá de satisfazer as exigências materiais e alimentares das sociedades, antes de corresponder a outras aspirações, supostamente mais "abstractas", e cuja ligação à própria tarefa de produção de riqueza não seja visível. (MBEMBE, 2013, p. 123).

Mbembe não é único nessa consideração. Ele, certamente leu Frantz Fanon. O martinicano refere-se desse elemento em dois momentos de sua imensa produção intelectual. Em Pele negra, máscaras brancas Fanon (2008, p. 92) vai dizer que "[...] compreender algo novo exige disponibilidade, preparação, exige uma nova formação. É utópico esperar do preto ou do árabe que se esforcem para inserir valores abstratos na sua $W_{\text {eltanschaunng }}^{7}$, quando eles mal conseguem comer o suficiente para matar a fome". Já em Os Condenados da Terra ele afirma: "[...] concedo que todas as provas que pudessem ser dadas da existência de uma prodigiosa civilização Songhai não mudam o fato de que os songhais de hoje são subalimentados, analfabetos, vivem entre céu e água com a cabeça vazia, os olhos vazios" (FANON, 1997, p. 174).

Entretanto, é Mbembe que nos atenta à necessidade de não existência de "casualidade em última instância", ou seja, que não se pode explicar tudo recorrendo a um determinismo qualquer das necessidades. Essa consideração trata, portanto:

\footnotetext{
7 O dicionário educalingo define Weltanschaunng como a orientação cognitiva fundamental de um indivíduo ou de toda uma sociedade. Essa orientação abrange tanto sua filosofia natural quanto seus valores fundamentais, existenciais e normativos. E, também, seus postulados ou temas, emoções, e sua ética. Outro sentido do termo é o de uma imagem do mundo imposta ao povo de uma nação ou comunidade, isto é, uma ideologia. O termo é um calco linguístico da palavra de origem alemã que significa literalmente visão de mundo ou cosmovisão. Essa palavra alemã é adotada regularmente em diversas línguas para expressar esses significados. Suas origens etimológicas remetem ao século XVIII. Ela é um conceito fundamental na filosofia e epistemologia alemã e se refere a uma percepção de mundo ampla. Adicionalmente, ela se refere ao quadro de ideias e crenças pelas quais um indivíduo interpreta o mundo e interage com ele. Disponível em https://educalingo.com/pt/dic-pt/weltanschauung. Acesso em 5 fev. 2020.
} 
[... de] precisar que dificilmente se poderá considerar a 'moldagem' política das sociedades pós-coloniais sempre que se desprezam o estado de miséria crónica em que vivem, o relativo desafogo ao qual poderiam aceder, as formas de lutas pela subsistência que são inventadas nesse âmbito, bem como as linguagens que permitem formular e encriptar essas lutas. (MBEMBE, 2013, p. 124)

O que essas considerações nos indicam? Esses chamados atestam a importância da discussão sobre as conflitualidades que se dão e sobre a educação escolar à volta das fogueiras, uma vez que a escola é compreendida, pelo menos nos contextos das escolas e comunidades em que tenho desenvolvido pesquisa, como "meio e possibilidade" de acesso a um mundo melhor, obviamente materializado. Portanto, não se podem ignorar essas lutas pela satisfação de necessidades que, aliás, constitui signo posto à volta da fogueira; tão pouco se deve ignorar também os usos (CERTEAU, 1995), as mil e uma maneiras de empregar as formalidades requeridas pelos "meios e possibilidades" de tal satisfação. Os sujeitos à volta da fogueira atiçam possibilidades de pensar a reinvenção cotidiana necessária aos desafios da educação e produção de conhecimentos em Moçambique, ou seja, possibilidades de tradução epistémica de saberes. O que nos atenta à consideração das necessidades é a sua preeminência na leitura sobre o cotidiano das comunidades moçambicanas e a proposta dialógica posta à fogueira.

\section{REFERÊNCIAS}

BRINGEL, Breno; ECHART, Enara. Movimentos sociais e democracia: os dois lados das "fronteiras". Caderno CRH, Salvador, v. 21, n. 54, p. 457-475, set./dez. 2008.

CASTIANO, José P.; NGOENHA, Severino E. A longa marcha duma 'educação para todos' em Moçambique. 3. ed. Maputo: Publifix, 2013.

CERTEAU, Michel de. A cultura no plural. Campinas, São Paulo: Papiros, 1995.

CÉSARIE, Aimé. Discurso sobre o colonialismo. Lisboa: Livraria Sá da Costa Ed., 1978.

FANON, Franz. Os condenados da terra. Rio de Janeiro: Civilização Brasileira, 1997.

FANON, Franz. Pele negra, máscaras brancas. Trad. Renato da Silveira. Salvador: EDUFBA, 2008.

FOUCAULT, Michel. Em defesa da sociedade: curso no Collège de France (1975-1976). São Paulo: Martins Fontes, 2005.

INE. Resultados definitivos do IV Recenseamento Geral de Populaşão e Habitação de Moçambique. Maputo, Moçambique: INE, 2019.

REPÚBLICA DE MOÇAMBIQUE. Lei n. 18/2018 de 18 de dezembro de 2018. Lei do Sistema Nacional de Educação, 2018.

REPÚBLICA POPULAR DE MOÇAMBIQUE. Lei n. 4/83 de 23 de marco de 1983. Lei do Sistema Nacional de Educação, 1983.

REPÚBLICA DE MOÇAMBIQUE. Lei n. 6/92 de 6 de maio de 1992. Revoga a primeira lei do Sistema Nacional de Educação, 1992.

MAZULA, Brasão. Educaşão, cultura e ideologia em Moçambique: 1975-1985. Maputo, 1995.

MBEMBE, Achile. África insubmissa: cristianismo, poder e estado na sociedade pós-colonial. Luanda: Edições Pedago, 2013.

MINEDH. Relatório do Estudo Holístico da Situação do Professor em Moçambique, 2015. Maputo, Moçambique: MINEDH, 2017.

MOORE, Carlos. Fela. Esta vida puta. Belo Horizonte: Nandyala, 2011.

NGOENHA, Severino Elias. Resistir a Abadon. Maputo: Paulinas Ed., 2017. 
OSÓRIO, Conceição; MACUÁCUA, Ernesto. Os ritos de iniciação no contexto actual: ajustamentos, rupturas e confrontos. Construindo identidades de género. Maputo: WLSA Moçambique, 2013.

SANTOS, Boaventura de Souza. A gramática do tempo: para uma nova cultura política. 2. ed., São Paulo: Cortez, 2008.

Submetido em marco de 2020 Aprovado em julho de 2020

\section{Informações do autor}

Roberto da Costa Joaquim Chaua

Faculdade de Educação e Psicologia, Universidade Rovuma - Moçambique E-mail: rocochaua17@yahoo.com.br

ORCID: https://orcid.org/0000-0002-4335-8972

Link Lattes: http://lattes.cnpq.br/1940225747324035 